\title{
Identification of Socioeconomic Variables Responsible for Diabetic Kidney Disease Among Bangladeshi Adults
}

\author{
Bhuyan KC* \\ Department of Statistics, Bangladesh \\ *Corresponding author: Department of Statistics, Jahangirnagar University, Dhaka, Bangladesh
}

\section{ARTICLE INFO}

Received: 幽 December 15, 2019

Published: 幽 January 06, 2020

Citation: Bhuyan KC. Identification of Socioeconomic Variables Responsible for Diabetic Kidney Disease Among Bangladeshi Adults. Biomed J Sci \& Tech Res 24(2)-2020. BJSTR. MS.ID.004021.

Keywords: Diabetic Kidney Disease; Socioeconomic Variables; Risk Ratio; Factor Analysis; Factor Loading

\begin{abstract}
The information provided here were analytical results of data collected from 808 adults who were interviewed by some doctors and nurses from their working places according to their convenience. Among the investigated adult's 4.7 percent were suffering from diabetic kidney disease which is one of the components of non-communicable diseases. In this study, 84.2 percent adults were urban residents and 4.0 percent of them were suffering DKD. Difference in residential accommodation was not associated with diabetic kidney disease. But rural adults were at higher risk of prevalence of DKD. The most responsible variable for DKD was residential origin followed by followed by occupation and smoking habit. These variables were detected by factor analysis as factor loadings of these variables were higher.
\end{abstract}

Abbreviations: ESKD: End-Stage Kidney Disease, DKD: Diabetic Kidney Disease, CV: Cardiovascular, CKD: Chronic Kidney Disease, BMI: Body Mass Index

\section{Introduction}

One of the causes of kidney failure is diabetes mellitus, a condition characterized by high blood glucose levels. Overtime, the high levels of glucose (sugar) in the blood damage the millions of tiny filtering units within each kidney. This eventually leads kidney failure. It indicates that hyperglycaemia contributes to the onset of and progression of Diabetic Kidney Disease (DKD) [1]. This disease is the most common cause of End-Stage Kidney Disease (ESKD) and it occurs in 50\% cases in the developed world [2]. People with DKD are not only at significant risk of progression to ESKD but have a greater concomitant increase in the risk for Cardiovascular (CV) morbidity and mortality [2]. Thus, poor glucose control is a risk factor for kidney function alteration both in type- 1 and typediabetes. It indicates that chronic kidney disease is associated with pre-diabetes, obesity a hypertension [3-6]. The risk of Chronic Kidney Disease (CKD) is related to physical inactivity both with and without adjustment for age, sex, race, and BMI [7]. Physical inactivity is again associated with lower rate of nephropathy and renal dysfunction in diabetic patients [6,8]. Again, obesity is associated with diabetes [9-11]. And hence obesity is also the cause of DKD. It was reported that approximately 463 million adults of ages 20-79 years worldwide were diabetic [12].

This figure will be increased up to 700 million in 2045 . Proportion of type 2 diabetes is increasing in most countries and 79 percent of adults with diabetes were living in low and middleincome countries [12]. Most of the diabetic people were in the age group 40-59 years and 374 million people are at risk of developing type 2 diabetes [12]. In another report it was mentioned that 1 in 5 diabetic patients were at the age above 65 years and 2 in 3 were urban residents [13,14]. Every year 4.2 million deaths were also reported [12]. The risk of diabetes among adults were also reported in different studies of home and abroad [10,11,15-20]. In one study, it was observed that most of the Bangladeshi urban adults (36.3\%) were suffering from diabetes [15]. The prevalence of diabetes in adults of ages 20-79 years was 7.4 percent in Bangladesh [15,16]. According to IDF the prevalence will be 13 percent by 2030 [14]. Diabetes was the targeted disease by WHO as it has some economic consequences also [ 20,21]. The earlier studies provided information that diabetes was the major health problem among 
Bangladeshi adults [22-24] and it was associated with obesity and some of the socioeconomic variables $[23,24]$.The present study was an attempt to investigate the risk and responsible factors of diabetic kidney disease among adults of Bangladesh . The specific objectives were

i. To investigate the risk factors of diabetic kidney disease,

ii. To detect the responsible factors for DKD.

\section{Methodology}

The data utilized for the present analysis were collected from 808 adults of Bangladesh by a group of doctors and nurses from their working places or nearby residences according to their convenience during academic session 2016 -17. According to the plan of study, the data related to different socioeconomic variables of the adults of ages 18 years and above were collected. Information related to the prevalence of non-communicable diseases among the adults and different aspects of treatment of the diseases were also recorded through a pre-designed and pre-tested printed questionnaire. The socioeconomic variables under study were residence, gender, religion, age, marital status, education, occupation, income, expenditure, body mass index, smoking habit, habit of taking restaurant and can-food, utilization of time, physical labor-intensive work, etc. Some of the variables were qualitative in character. But for analytical purpose all the variables were measured in nominal scores. In some studies, both in home and abroad, it was noted that diabetes were associated with level of obesity [16,22-25]. Again, level of obesity was measured by Body Mass Index (BMI). The BMI was measured by weight in kg / (height in meter)2 [21,26,27]. The adults were classified as underweight [ $\mathrm{BMI}<20$ ], normal [BMI $20-<25]$, overweight [ $\mathrm{BMI}=25-<30]$, and obese [ BMI30] [21].

Table 1: Distribution of diabetic kidney patients according to different socioeconomic variables.

\begin{tabular}{|c|c|c|c|c|c|c|}
\hline \multirow{3}{*}{ Socioeconomic variables } & \multicolumn{4}{|c|}{ Prevalence of diabetes and kidney diseases } & \multirow{2}{*}{\multicolumn{2}{|c|}{ Total }} \\
\hline & \multirow{2}{*}{$\begin{array}{c}\text { Yes } \\
\mathbf{N}\end{array}$} & \multicolumn{3}{|c|}{ No } & & \\
\hline & & $\%$ & $\mathbf{N}$ & $\%$ & $\mathbf{N}$ & $\%$ \\
\hline \multicolumn{7}{|l|}{ Residence } \\
\hline Rural & 11 & 8.6 & 117 & 91.4 & 128 & 15.8 \\
\hline Urban & 27 & 4 & 653 & 96 & 680 & 84.2 \\
\hline Total & 38 & 4.7 & 770 & 95.3 & 808 & 100 \\
\hline \multicolumn{7}{|l|}{ Gender } \\
\hline Male & 30 & 5.3 & 530 & 94.7 & 563 & 69.7 \\
\hline Female & 8 & 3.3 & 237 & 96.7 & 245 & 30.3 \\
\hline \multicolumn{7}{|l|}{ Religion } \\
\hline Muslim & 31 & 4.3 & 695 & 95.7 & 726 & 89.9 \\
\hline Non-Muslim & 7 & 8.5 & 75 & 91.5 & 82 & 10.1 \\
\hline \multicolumn{7}{|l|}{ Marital status } \\
\hline Currently married & 28 & 6.8 & 383 & 93.2 & 411 & 50.9 \\
\hline Currently single & 10 & 2.5 & 387 & 97.5 & 397 & 49.1 \\
\hline Age (in years) & & & & & & \\
\hline
\end{tabular}

The adults were divided into two groups. In one group there were 38 diabetic -cum-kidney patients. Rest of the adults (770) were either free of any disease or were suffering from multiple diseases. The association of socioeconomic variables with prevalence of diabetic kidney diseases were by Chi - square test, where significant association was decided if $\mathrm{p}$ - value of any test statistic was $<0.05$. The risk ratio was calculated for all dichotomous data [28]. Factor analysis was done to detect the most responsible factor for DKD. Higher factor loading of any variable indicates the more responsible variable for the disease [ 20, 26-28]

\section{Result}

It was mentioned that the total investigated adults were 808 . Among these adults, 84.2 percent (Table 1) were from urban area and 4 percent of them were suffering from diabetic kidney disease. The percentage of adults in the sample suffering from DKD was 4.7 only. However, there was significant differences in the percentages of DKD patients of urban and rural areas [ $=5.133$, p-value= $0.0 .023]$. The risk ratio 2.08 indicated that for rural adults the risk of DKD was more than 2 times compared to that of urban adults. The percentage of male adults was 69.7 and 5.3 percent of them were diabetic kidney patients. The female diabetic kidney patients were 3.3 percent and they had 63 percent more risk of diabetic kidney diseases [ R.R.=1.63] compared to the risk of male adults. However, there was no significant association between gender variation and variation in the prevalence of diabetic kidney diseases [ = 1.622, $\mathrm{p}$ value $=0.085]$. The percentage of Muslim respondents was 89.9 and 4.3 percent of them were diabetic kidney patients. The percentage of non-Muslim diabetic kidney patients was 8.5. But this differential percentages of diabetic kidney patients between two religious groups were not statistically significant $[=2.993, \mathrm{p}$-value $=0.0 .084]$. But the non-Muslims adults were at higher risk of diabetic kidney diseases by 200 percent [ R.R. $=2.00]$. 


\begin{tabular}{|c|c|c|c|c|c|c|}
\hline$<20$ & 2 & 5.6 & 34 & 69.4 & 36 & 4.5 \\
\hline $20-30$ & 8 & 2.6 & 304 & 74 & 312 & 38.6 \\
\hline $30-40$ & 5 & 7.6 & 61 & 86.4 & 66 & 8.2 \\
\hline $40-50$ & 6 & 4.3 & 132 & 74.6 & 138 & 17.1 \\
\hline $50+$ & 17 & 6.6 & 239 & 65.6 & 256 & 31.7 \\
\hline \multicolumn{7}{|l|}{ Education } \\
\hline Illiterate & 1 & 4.5 & 2 & 95.5 & 22 & 2.7 \\
\hline Primary & 6 & 10.7 & 50 & 89.3 & 56 & 6.9 \\
\hline Secondary & 10 & 7.8 & 119 & 92.2 & 129 & 16 \\
\hline Higher & 21 & 3.5 & 580 & 96.5 & 601 & 74.4 \\
\hline \multicolumn{7}{|l|}{ Occupation } \\
\hline Agriculture and unskilled labor & 8 & 22.9 & 27 & 77.1 & 35 & 4.3 \\
\hline Business and skilled labor & 2 & 2.6 & 74 & 9.4 & 76 & 9.4 \\
\hline Service & 10 & 5.5 & 173 & 94.5 & 183 & 22.6 \\
\hline Housewives and others & 18 & 3.5 & 496 & 96.5 & 514 & 63.6 \\
\hline \multicolumn{7}{|l|}{ Income ( in 000 taka) } \\
\hline$<30$ & 5 & 3.1 & 154 & 96.9 & 159 & 19.7 \\
\hline $30-60$ & 6 & 5.2 & 110 & 94.8 & 116 & 14.3 \\
\hline $60-90$ & 5 & 8.1 & 57 & 91.9 & 62 & 7.7 \\
\hline $90+$ & 22 & 4.7 & 449 & 95.3 & 471 & 58.3 \\
\hline \multicolumn{7}{|l|}{ Smoking habit } \\
\hline Yes & 12 & 8.5 & 130 & 91.5 & 142 & 17.6 \\
\hline No & 26 & 3.9 & 640 & 96.1 & 666 & 82.4 \\
\hline \multirow{3}{*}{ Socioeconomic variables } & \multicolumn{4}{|c|}{ Prevalence of diabetes and kidney diseases } & \multirow{2}{*}{\multicolumn{2}{|c|}{ Total }} \\
\hline & Yes & & No & & & \\
\hline & $\mathbf{N}$ & $\%$ & $\mathbf{N}$ & $\%$ & n & $\%$ \\
\hline \multicolumn{7}{|l|}{ Family expenditure ( in 000 taka) } \\
\hline$<40$ & 7 & 3.7 & 181 & 96.3 & 188 & 23.3 \\
\hline $40-50$ & 9 & 6.1 & 138 & 93.9 & 147 & 18.2 \\
\hline $50-60$ & 6 & 3.2 & 179 & 96.8 & 185 & 22.9 \\
\hline $60+$ & 16 & 5.6 & 272 & 94.4 & 288 & 35.6 \\
\hline \multicolumn{7}{|l|}{ Taking restaurant food } \\
\hline Yes & 26 & 5.5 & 449 & 94.5 & 475 & 58.8 \\
\hline No & 12 & 3.6 & 321 & 96.4 & 333 & 41.2 \\
\hline \multicolumn{7}{|l|}{ Use of can food } \\
\hline Yes & 29 & 5.6 & 493 & 94.4 & 522 & 64.6 \\
\hline No & 9 & 3.1 & 277 & 96.9 & 286 & 35.4 \\
\hline \multicolumn{7}{|l|}{ Obesity } \\
\hline Underweight & 3 & 2.8 & 104 & 97.2 & 107 & 13.2 \\
\hline Normal & 18 & 4.4 & 387 & 95.6 & 405 & 50.1 \\
\hline Overweight & 16 & 6.1 & 245 & 93.9 & 261 & 32.3 \\
\hline Obese & 1 & 2.9 & 34 & 97.1 & 35 & 4.3 \\
\hline \multicolumn{7}{|l|}{ Utilization of time } \\
\hline Academic activities & 8 & 3.9 & 196 & 96.1 & 204 & 25.2 \\
\hline Reading and watching T.V. & 5 & 2.9 & 167 & 97.1 & 172 & 21.3 \\
\hline Games and sports & 1 & 1.8 & 55 & 98.2 & 56 & 6.9 \\
\hline Paper reading and use of mobile & 18 & 8.1 & 205 & 91.9 & 223 & 27.6 \\
\hline Use of T.V. and mobile & 6 & 3.9 & 147 & 96.1 & 153 & 18.9 \\
\hline Physical exercise & & & & & & \\
\hline
\end{tabular}




\begin{tabular}{|c|c|c|c|c|c|}
\hline Yes & 19 & 4.6 & 395 & 95.4 & 414 \\
\hline No & 19 & 4.8 & 375 & 95.2 & 394 \\
\hline Total & 38 & 27.7 & 584 & 72.3 & 808 \\
\hline
\end{tabular}

The percentage of married adults was 50.9 and 6.8 percent of them were suffering from diabetic kidney diseases. The married adults were at higher risk of the diseases compared to the risk of single adults [ R.R. $=2.70$ ]. There were significant differences in the percentages of married and single adults suffering from diabetic kidney diseases $=8.335$, $\mathrm{p}$-value $=0.015]$. The diabetic kidney patients of different age groups were similar in proportions 6.642 , $\mathrm{p}$-value $=0.156]$. But the adults of ages 40 years and above were at 61 percent more risk of the disease compared to the risk of adults of ages less than 40 years [ R.R.=1.61]. The percentage of higher educated adults was 74.4 and 3.5 percent of them were suffering from diabetic kidney diseases. This percentage among illiterate adults was 4.5. The differences in percentages of diabetic adults of different levels of education were significant [ $=9.152$, p-value $=0.0 .02]$. The lower level educated adults were at higher risk of diabetic kidney diseases by an amount 235 percent compared to the risk of educated adults [ R.R.=2.35]. The adults were classified by agriculturists and unskilled labors, businessmen and skilled labors, service persons and others including housewives [29]. The percentages of these 4occupational groups of adults were 4.3,9.4, 22.6 and 63.6, respectively. Among the agriculturists and unskilled labors 22.9 percent were diabetic kidney patients. This proportion among businessmen and skilled labors was 0.026 .

The proportions of diabetic kidney patients among adults of different professions were significantly different [= 28.356, $\mathrm{p}$-value $=0.000]$. The risk of diabetic kidney diseases among different professional groups compared to the risk of another occupational group was almost double [ R.R.=1.94]. Maximum (8.1\%) diabetic kidney patients were observed in those families where monthly family income was 60 thousand and above but less than 90 thousand. But a big group of adults (58.3\%) were coming from highest income group of families (taka 90 thousand and above). Diabetic kidney patients in this group were 4.7 percent. However, there was no significant difference in the proportions of diabetic kidney patients of different income groups of adults [ $=2.483$, p-value=0.478]. The risk of the disease among the rich adults compared to the risk of adults of other income groups were almost similar [ R.R = 1.02]. The proportion of middle-income families [ income 30 - 90 thousand taka] was 0.22 . The risk is higher $[$ R.R. $=1.44]$ among the adults of this income level compared to the adults of other income levels. Highest (taka 60 thousand and above) family expenditure was noted among 35.6 percent families and this was the biggest group of families. In this families, 5.6 percent adults were the patients of diabetic kidney disease. Highest percentage $(6.1 \%)$ of patients of this disease was observed in the families spending 40 - 50 thousand taka.

However, the differences in the proportions of diabetic kidney disease patients in families spending different amounts of money were not significant $[=2.410, \mathrm{p}$-value $=0.492]$. Adults of families spending taka 40 - 50 thousand as family expenditure were at 40 percent more risk of diabetic kidney disease compared to the risk of adults of other groups[ R.R.=1.40] The percentage of overweight adults was 32.3 and 6.1 percent of them were the patients of diabetic kidney disease. Lowest percentage $(2.8 \%)$ of sufferers were noted among the normal adults. Though insignificant association between level of obesity and prevalence of diabetic kidney disease was noted [ $=2.374, \mathrm{p}$-value $=0.498]$, still overweight and obese adults were at higher risk of the disease by an amount 40 percent compared to the risk of adults of other two levels of obesity [ R.R.=1.40]. Longer duration of use of mobile phone and watching T.V. for long time are sedentary activities. By doing these two activities 46.5 percent adults were passing their times and higher proportion of them were suffering from the disease (12\%).

However, prevalence of diabetic kidney disease was not dependent on the utilization of time by the adults [ $=8.434$, $p$ - value $=0.077]$. Though insignificant association between prevalence of diabetic kidney disease and utilization of time was noted, still the adults involved in sedentary activities were at higher risk of the disease compared to the risk of patients of diabetic kidney disease not involved in sedentary activities [ R.R.=1.97]. Most of the adults were doing physical exercise ( $51.2 \%$ ) but this study did not signify any evidence that physical exercise had any positive impact in reducing the patients of diabetic kidney[ $=0.024$, $\mathrm{p}$-value $=0.876]$, because the proportions of affected adults by the disease were almost same irrespective of doing or not doing physical exercise. The risk of affecting by the disease was almost similar. The value of risk ratio for the adults not doing any physical exercise was 1.05. The percentage of smoker adults was 15.8. But higher proportion of them (8.5\%) were suffering from diabetic kidney disease. Significant association between smoking habit and prevalence of diabetic kidney disease was noted [ $=5.399, \mathrm{p}$ - value $=$ 0.020] and smokers were at higher risk of the disease [ R.R.=2.16].

The study indicated that irrespective of taking or not taking restaurant food the proportions diabetic kidney patients of both group of adults were not significantly different as was observed by chi-square test $[=1.528, \mathrm{p}$ - value $=0.216]$. However, those who used to take (58.8\%) were at higher risk by 52 percent compared to the risk of adults who did not take restaurant food [R.R.= 1.52]. This analysis also did not show any significant association between habit of taking can food and prevalence of diabetes kidney disease [ = 2.392, $\mathrm{p}$-value $=0.122]$. Most of the adults $(64.6 \%)$ were habituated in taking can food and 5.6 percent of them were affected by the disease. These group of adults were at higher risk of prevalence of the disease compared to the adults who were not habituated in taking can food [ R.R = 1.77]. 


\section{Factor Analysis}

From the analysis presented above it was observed that the variables residence, marital status, education, occupation, and smoking habit were significantly associated with diabetic kidney disease. But the study of association does not indicate the most responsible variable for the variation of prevalence of DKD. The most responsible variable can be detected by factor analysis, where higher value of a factor loading indicates the more responsible variable for the variation in the data set. To identify the most responsible variable, factor analysis was done using all the variables under study irrespective of significant or insignificant association of the variables with diabetic kidney disease. The inclusion of the variables was satisfactory as $\mathrm{KMO}=0.0 .452$ which provided $=$ 226.826, $\mathrm{p}$-value $=0.000$. During factor analysis it was noted that the communalities of the variable's education, restaurant food, can food and BMI were less than 0.40 [30]. So, these 4 variables were dropped from the analysis. With the remaining variables again factor analysis was done. During this analysis also the inclusion of the variables was perfect as the $\mathrm{KMO}=0.508=14.600, \mathrm{p}$-value $=$ 0.000 .

The final included variables had the capacity to explain 48.089 percent variation in the data set through the detection of two components under the restriction of characteristic root 2 . The results of the factor analysis were presented in (Table 2). It was observed that the variable residence followed by occupation and smoking habit were the three most responsible factors for the diabetic kidney disease. Gender was not an important factor for DKD. The next two responsible variables for the disease were family expenditure and utilization of time.

Table 2: Results of factor analysis.

\begin{tabular}{|c|c|c|c|}
\hline Variable & Communality & Coefficient of factor - 1 & Coefficient of factor 2 \\
\hline Residence & 0.573 & 0.754 & 0.067 \\
\hline Gender & 0.399 & 0.144 & 0.615 \\
\hline Age & 0.794 & -0.498 & 0.739 \\
\hline Marital status & 0.614 & 0.495 & -0.608 \\
\hline Smoking habit & 0.461 & 0.572 & 0.366 \\
\hline Utilization of time & 0.482 & -0.55 & 0.424 \\
\hline Occupation & 0.526 & 0.706 & 0.166 \\
\hline Income & 0.309 & -0.451 & -0.325 \\
\hline Expenditure & 0.376 & -0.539 & -0.293 \\
\hline
\end{tabular}

\section{Discussion}

The risk of diabetic kidney disease was reported in both home and abroad [1-9,31]. It was also reported that diabetes was the major health hazard among Bangladeshi adults [10,16, 20,32]. The health hazard of diabetic kidney diseases was noted irrespective of residence, marital status, education, occupation, smoking habit. It was evident from the present analysis that rural adults had higher risk of DKD compared to urban adults. Variation in the prevalence of DKD according to the variation of gender, religion, age, income, physical exercise, habit of taking restaurant food and can food was not statistically different. Even the value of body mass index did not influence the diabetic kidney diseases. The diabetic kidney diseases was not associated with sex, but male adults had higher risk of prevalence of the disease. Both income and expenditure had no positive impacts on the prevalence of DKD. Though diabetes is a lifestyle disease and it is the disease of the rich [13], but the present analysis did not indicated that diabetic kidney diseases were dependent on family income and expenditure, rather the diseases were dependent on occupation.

The habit of taking restaurant food and can food had no influence in enhancing the diseases. But those who were habituated in taking restaurant and can food they were at higher risk of DKD. Smoking habit had positive impact in enhancing the disease. The smokers were at higher risk of affecting by the DKD. Their risk was more than double than the risk of non-smokers. The risk of DKD was more than $150 \%$ for the adults who were habituated in taking restaurant food and can food. Those who were not physically active, their risk of prevalence of DKD was almost two times than the risk of adults doing physical work. Overweight and obese adults had more chance of affecting by the diabetic kidney diseases. It was also documented that smoking is a risk factor for renal damage in diabetic patients [32]. The present analysis also supported this phenomenon.

\section{Conclusion}

The analytical results presented in the paper were based on the data collected from 808 adults of ages 18 years and above by some doctors and nurses from and nearby their working places. As a result, most of the investigating (84.2\%) units were from urban area. But higher proportion of rural adults compared to urban adults were affected by the DKD. Significant association of residence and prevalence of diabetic kidney disease was noted. The risk of prevalence of DKD among rural adults was more than double compared to the risk for the urban adults. Insignificant association between prevalence of DKD and gender variation was noted. But female adults (30.3\%) were at higher risk of affecting by the disease [R.R.=1.61]. Among the adult's 89.9 percent were 
Muslims and 4.3 percent of them were suffering from diabetic kidney disease. However, religion and prevalence of DKD were not statistically associated, but the risk of the disease was more among non- Muslims (R.R.=1.91). Among the adult's 50.9 percent were married.

Marital status and prevalence of DKD were significantly associated. The married adults were at higher risk of DKD. The prevalence rates of DKD was not significantly different for adults of different ages and those who were of ages 40 years and above were at higher risk of diabetic kidney disease. The prevalence of DKD was higher among primary and secondary educated adults. The variation in the prevalence rates according to the variation in the levels of education was significantly different. Adults of lower level education were at high risk of affecting by DKD. Significant differences in the prevalence rates were noted among adults of different levels of occupation. The risk [R.R.=1.94] of diabetic kidney disease among businessmen, skilled lobors and service persons was more compared to the risk of other professionals. The prevalence rates of DKD among adults of different levels of income were not significantly different. But the risk of DKD among adults of different income group was similar compared to the risk of higher income group of adults .Insignificant differences in the prevalence rates were noted for adults of different expenditure levels and adults spending 40-50 thousand taka as family expenditure were at higher risk of DKD.

Physical inactivity and involved in sedentary activities were not influencing factors for prevalence of diabetic kidney disease. But the risk of DKD was more among the adults who were involved in sedentary activities. Habit of taking restaurant food and can food did not enhance the risk of DKD. But those who were taking restaurant food, and can food were at higher risk of DKD compared to those adults who were not usually take restaurant and can food. Body mass index was not significantly associated with prevalence of diabetic kidney disease. But overweight and obese group were at higher risk [R.R.=1.40] Due to upward social mobility, increased mechanical movement and more involvement in economic activities the prevalence of diabetic kidney disease cannot be avoided. But the prevalence rate can be controlled, if people can take some initiative

i. To control diet by taking healthy and homemade food,

ii. To avoid more sugar-based food, salty food and food having unsaturated fat,

iii. To be careful about the self-care behaviour and avoid smoking,

iv. To do some physical labor and /or physical exercise or at least walk a while whenever possible.

v. To join the blood screening program,

vi. To adhere the lifelong medical therapy by the patients,

vii. To avoid the increase in body weight.
Health planners and social activists can do a lot to encourage the people to follow the above steps.

\section{References}

1. Richard JM, George J, Elif IF (2017) Effects of glycaemia management on diabetic kidney disease, World Jour Diabetes 8(5): 12 -186.

2. (2016) ADA Standards of Medical Care in Diabetes-2016. summary Revisions diabetes Care 39(1): S4 -S5.

3. Echouffo Tcheugui JB, Narayan KM, Weisman D, Golden SH, et al. (2016) Association between pre-diabetes and eisk of chronic kidney disease: a systematic review and meta-analysis. Diabetic Medicine 33(12): 16151624.

4. Deloitte (2011) Two of a KinD Kidney Health Australia.

5. Hall JH Brands DW, Henegar JR (1998) Kidney function as a cause and a consequence of obesity hypertension, Clin Exp Pharmacol Physiol 25: 58-64.

6. Kriska AM, Laporte RE Patnick SL (1991) The association of physical activity and diabetic complications I individuals with insulin dependent mellitus: the epidemiology of diabetes complications study vii. Jour Clin Epidemiology 44: 1207-1214.

7. Stengel B, Tarver Carr ME, Powe NR, Eberhardt MS, Brancati FL (2003) Lifestyle factors, obesity, and the risk of chronic kidney disease, Epidemiology 14(4): 479-487.

8. Mark J Sarnale (2003) Cardiovascular disease complications in Chronic kidney disease, Amer Jour of Kidney diseases 41(5): 11-15.

9. Bhuyan KC, Fardus J (2019) Level of obesity and socioeconomic factors of a group of adult people of Bangladesh: A factor analysis approach, Amer, Jour. Data Mining and Knowledge Discovery 4(1): 8-14.

10. Akter S, Rahaman MM, Sarah KA, Sultan P (2014) Prevalence of diabetes and pre-diabetes and their risk factors among Bangladeshi adults: A Nationwide survey, Bulletin of the WHO 92: 204-213 A.

11. Mokdad AH, Ford ES, Bowman BA, Dietz WH, Vinicor F, et al. (2003) Prevalence of obesity, diabetes, and obesity-related health risk factors 2001. JAMA 289: 76-79.

12. International Diabetes Federation (2019) Diabetes Atlas, $9^{\text {th }}$ edn, IDF, Brussels, Belgium.

13. WHO: Fact sheets / detail / obesity-and-overweight (2018)?

14. International Diabetes Federation (2011) Country estimates table, Diabetes Atlas $6^{\text {th }}$ edn, IDF.

15. Mortuza A, Bhuyan KC and Fardus F (2018) A study on identification of socioeconomic variables associated with no-communicable diseases among Bangladeshi adults AASCIT 4(3): 24-29; http://www.aascit.org. journal/ajbse.

16. Saquib N, Saquib J, Ahmed T, Khanam MA, Cullen MR (2012) Cardiovascular diseases and type II diabetes in Bangladesh: a systematic review ant meta- analysis of studies between 1995-2010. BMC Public Health 12: 434

17. Rabi DM, Edwards AL, Southern DA, Svension LW, Sargious PN, et al. (2006) Association of socioeconomic status and risk of diabetes related mortality with diabetes prevalence and utilization diabetes care services, BMC Public Health Services Research 6: 124.

18. WHO (2018) About Chronic Respiratory diseases? World Health Organization Retrieved 2018: 10-31.

19. Abegunde DO, Staniole A (2006) An estimation of the economic impact of chronic non-communicable diseases in selected countris. WHO workin paper, Geneva, World Health Organization, Department of Chronic Disease and Health Promotion?

20. Fardus J Bhuyan, KC (2016) Discriminating diabetic patients of some rural and urban areas of Bangladesh: A discriminant analysis approach, Euromediterrean Bio Jour 11(9): 134-140. 
21. Bhuiyan D, Bhuyan KC (2019) Discriminating Bangladeshi adults by non-communicable diseases, Rehabilitation Science 4(3): 35-43.

22. Bhuyan KC, Ahmed Md, Fardus J (2017) Socioeconomic factors associated with overweight an obesity: A case study among adult people of Bangladesh. AJSE 16(2): 119-124.

23. Paymane A, Miranda P (2018) Images of measurements of obesity BM] 360.

24. Calamusa G, Amodio E, Costantino C, Sistron CL, Garvan CW, et al. (2004) Proportions, odds and risk. Radilogy 230(1): 12 -19.

25. Bhuyan KC (2019) A note on factor analysis applied in medical research. Archives in Biomed Eng. And Biotech 1(4): 1-3.

26. Bhuyan KC (2004) Multivariate Analysis and its Applications. New Central Book Agency(P) ltd. India.

27. Yotoka T (1983) Some criteria for variable selection in factor analysis. Behaviormetrika 13: 31-45.

ISSN: 2574-1241

DOI: 10.26717/BJSTR.2020.24.004021

Bhuyan KC. Biomed J Sci \& Tech Res

(C) This work is licensed under Creative

Submission Link: https://biomedres.us/submit-manuscript.php
28. Syed MS, Debra N, Muhammad HR, Musa R, Gul N (2004) Assessing obesity and overweight in a high mountain Pakistani population. Tropical Medicine and International Health 9(4): 526-532.

29. Jain K (2018) Value of communality. Amity Business School.

30.William FK, Garabad E (1999) Proteinuria, albuminuria, risk, assessment, detection, elimination (PARADE): A position paper of the National Kidney Foundation. Amer Jour of Kidney Diseases 33(5): 10041010.

31. Bhuyan KC, Fardus J, Rahaman S (2016) Relationship between socioeconomic factors and diabetes among urban and rural people of Bangladesh. Global Journal of Quantitative Science 3(4).

32. Orth SR, Ritz, E, Schrier RW (1997) The renal risk of smoking. Kidney Int 51: 1669-1677.

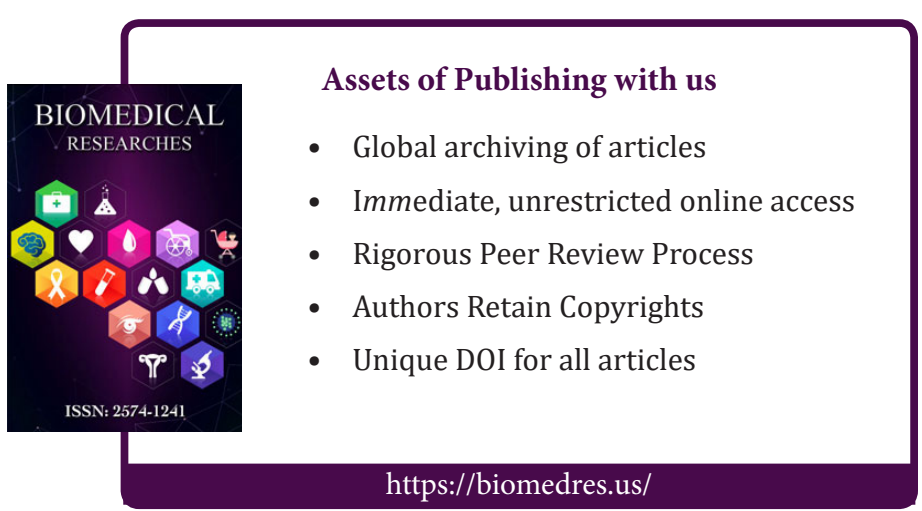

